\title{
Overview of sorption analysis capabilities for meso- and microporous zeolites nanomaterials
}

\author{
S. Tokmeilova* (iD), E.V. Maraeva \\ Saint Petersburg Electrotechnical University «LETI», \\ Prof. Popova St., 5, Saint Petersburg 197376, Russia \\ * Corresponding author: ak_saya@mail.ru
}

This article belongs to the regular issue.

(C) 2021, The Authors. This article is published in open access form under the terms and conditions of the Creative Commons Attribution (CC BY) license (http://creativecommons.org/licenses/by/4.O/).

\section{Abstract}

In this paper we consider the main application features of the thermal desorption method of inert gases, implemented on the Sorbi MS (Meta, Russia) device, for the analysis of meso- and microporous materials. Recommendations on the choice of measurement modes for stable operation of the Sorbi MS device are offered (including recommendations on mass, sample preparation mode). The article presents the results of the micropores analysis by the t-plot and Sing method.

\section{Keywords}

micropores

mesopores

capillary condensation

sorption hysteresis

Received: 27.04.2021

Revised: 12.06.2021

Accepted: 30.06.2021

Available online: 07.07.2021

\section{Introduction}

Gas sorption methods are commonly used to characterize porous materials. Porous materials are widely used in micro- and nanoelectronics. According to the classification of pores by size, micropores are less than $2 \mathrm{~nm}$ in size, mesopores are in the range from 2 to $50 \mathrm{~nm}$ [1]. At present, nitrogen sorption at $77 \mathrm{~K}$ has become a standard tool for the analysis of materials with pores in a range of $0.5^{-}$ $50 \mathrm{~nm}$. The mechanism of nitrogen sorption at $77 \mathrm{~K}$ occurs in the following way. At a low relative pressure (0.02o.1), the filling of micropores with adsorbate begins. The monolayer adsorption occurs after the completion of adsorption in micropores. Capillary condensation is observed in relatively small mesopores when the relative pressure and pore width correspond to the Kelvin equation. The desorption isotherm is obtained by reversing the adsorption process, releasing the liquid adsorbate and decreasing the equilibrium relative pressure [2]. The evaporation process takes place from the meniscus of the condensed liquid.

In the case of polymolecular adsorption, the adsorption potential interaction does not change with the distance from the surface of micropores, as a result of dispersion potentials overlapping of closely spaced pore walls [3]. As a result, adsorption in the entire volume of micropores becomes equiprobable to adsorption on their surface (micropores volumetric filling). The adsorption potential interaction of adsorptive molecules with microporous materials is much higher than with the surface of mesoscale materials. All this together determines some peculiarities and imposes certain restrictions on the applicability of the Brunauer-Emmett-Teller (BET) method. Therefore, other procedures are used for the micropore adsorption isotherms analysis, the so-called comparative methods of analysis, which make it possible to isolate the contribution of adsorption in the volume of micropores and to calculate the size of the mesopores and macropores surface. Currently, a large number of comparative methods are known that are used to determine the specific surface area of a microporous material and to estimate the volume of micropores in the presence of mesopores: t-method, Sing's as-method and others.

The works [4-7] illustrating the current state of the question of the specific surface area analysis of mesoporous materials are presented. Mesoporous materials are widely used in practice (bioengineering, sensorics of gaseous media and environmental monitoring, power engineering, lithium-ion batteries), are used as adsorbents and catalysts for oil refining processes. In all cases, the porous structure parameters play a key role.

The paper [4] presents and discusses the kinetic results of nitrogen adsorption and desorption experiments performed at $77 \mathrm{~K}$ on one aluminum-based and three materials based on carbon, differing in their microporous and mesoporous nature. The paper is devoted to the study of transport phenomena during adsorption / desorption experiments in pores of various sizes. The authors of the article noted that the rates of transport phenomena 
change significantly with the gradual filling / emptying of the pores.

The authors of [5] synthesized and investigated CoO3D ordered mesoporous carbon nitride (CoO@mpgCN) catalyst. The authors managed to find out that the significant catalytic performance of $\mathrm{CoO} @ \operatorname{mpgCN}$ was due to its uniformly distributed mesopores, large specific surface area, and high electron transferability at the active $\mathrm{CoO}$ sites. The textural parameter and the mesoporous extent of materials originated from parent template were examined by nitrogen adsorption-desorption isotherm along with corresponding BET surface area and pore distribution analyses.

The authors of [6] aimed to explore a facile route to synthesize mesoporous zinc silicate composites. The specific surface area and the pore properties of the samples were tested by the Brunauer-Emmett-Teller (BET) method based on $\mathrm{N}_{2}$ adsorption / desorption measurements on Quantachrome Autosorb-IQ2. The authors provided the $\mathrm{N}_{2}$ adsorption / desorption isotherms and pore size distributions of ZS-3 and ZS-5 that are rather different in structure. The fact that the structure is mesoporous is indicated by the increase of adsorbed nitrogen at relative pressure $P>0.45$ and related to the multilayer adsorption and capillary condensation of $\mathrm{N}_{2}$. The excellent adsorption property endows the composite with potential application in the field of dye wastewater treatment.

The authors of [7] attempted to enhance nitrogen adsorption capacity modified $\mathrm{X}$ zeolite adsorbent. For this, procedures including both $\mathrm{NH}_{4}^{+}$treatment and $\mathrm{Ca}^{2+}$ ionexchange were carried out. These modifications lead to a hierarchical mesopore-micropore structure with a multilayer $\mathrm{N}_{2}$ adsorption capacity. The properties of adsorbents are characterized by $\mathrm{N}_{2}$ adsorption-desorption in $77 \mathrm{~K}$, $\mathrm{XRD}$, and XRF analysis. In paper [7] adsorption isotherms are modeled by Langmuir, Dual-Site Langmuir (DSL), Freundlich, and Langmuir-Freundlich (Sips) models, and the corresponding parameters are determined. These adsorbents can be used effectively in the helium purification by the pressure swing adsorption (PSA) process, which is based on nitrogen adsorption.

It is known that the zeolites considered in this work are microporous materials. However, catalytic processes require materials containing both meso- and macropores. At the same time, the advanced system of zeolite micropores has a significant effect on the rate of the reactions. In this regard, it is necessary to develop analysis techniques that provide simultaneous control of the microand mesoporous structure of materials.

The aim of this paper is to consider the application peculiarities of the thermal desorption method of inert gases, implemented on the Sorbi MS (Meta, Russia) device, for the analysis of meso- and microporous zeolite materials.

\section{Experimental}

In this work, zeolites of the type ZSM-5 (samples 1,3) and BETA (samples 2,4-6) were investigated. Aluminum hydroxide (AH), including silica addition, was selected as the binder. The sample synthesis features and the selection of the peptizers are shown in Table 5 .

Zeolites were synthesized at the Irkutsk National Research Technical University. In the previous paper [8], the results of the studying the properties of compositions in the mesopore range are presented; here we will emphasize the analysis of micropores.

Adsorption isotherms were built on the basis of the sorption study data obtained. The samples were studied by nitrogen sorption at $77 \mathrm{~K}$ on the Sorbi MS device. The device works by comparing the volumes of adsorbate gas sorbed by the test sample and the standard sample. The specific surface area is measured using the 4-point BET method. Micropores volume was determined on the basis of analysis of inert gas adsorption isotherms.

\section{Results and Discussion}

\subsection{Investigation of capillary condensation pro- cesses, sorption hysteresis}

A characteristic feature of adsorption in mesopores is associated with capillary condensation, which leads to filling the mesopores volume with a liquid adsorbate phase at a relative pressure, for example, nitrogen vapor at $77 \mathrm{~K}$, $0.4<P / P_{\mathrm{O}}<1$. As a rule, the process of capillary condensation is irreversible. This means that the magnitude of sorption with increasing pressure of the sorbent does not coincide with the magnitude of sorption with decreasing pressure. In this case, a characteristic hysteresis is formed on the sorption isotherm, formed by mismatched branches of adsorption and desorption (Fig. 1) [3].

\subsection{Recommendations on the choice of measure- ment modes of the Sorbi MS device}

During researching the parameters of the nanomaterials porous structure by the sorption method, it is important to correctly estimate the mass of the adsorbent material required for the study, select the sample preparation mode, and set the range of the relative partial pressure variation of the adsorbate gas at which the measurement will be carried out.

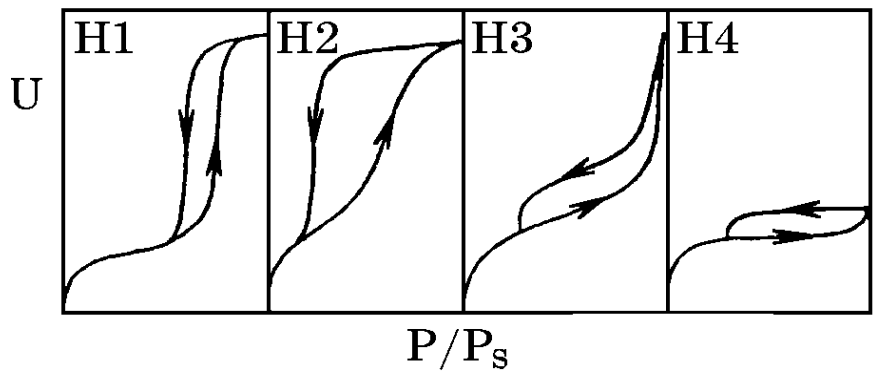

Fig. 1 Characteristic types of capillary-condensation hysteresis loops according to the IUPAC classification. Adapted from [3] 


\subsubsection{Determination of the analyzed material mass and sample preparation}

The features of the thermal desorption method realized in Sorbi MS are discussed in $[9,10]$. When studying compositions by the thermal desorption method of nitrogen, the choice of the analysed material mass is determined by two factors: the possibility of obtaining a stable desorption signal, which is used to calculate the volume of desorbed gas, and the range of the total measured surface $S=S_{\mathrm{sp}} \cdot m$. For example, the selected masses for various series of zeolite compositions that provide a stable desorption signal are shown in Table 1.

\subsubsection{Modes selection and sample preparation of the analyzed material}

Sample preparation of the analysed material, as a rule, consists in controlled heating of the sample in a flow of inert gas (helium). Preparation is necessary, first of all, to remove moisture and surface contamination. Variable sample preparation modes are heating temperature and time. Table 2 shows, for example, the results of measuring the parameters of the porous structure of some samples depending on the conditions of preliminary degassing.

Also all samples were subjected to a single annealing procedure in a muffle furnace for 1 hour. This procedure is required in case of long-term storage or transportation of samples in high humidity conditions. The results of measuring the specific surface area for a sample of the BEA type are presented in Table 3.

As can be seen from Table 3, in the case of long-term storage of zeolite samples in high humidity conditions, the measured specific surface area of the samples decreases by 2-3 times. Zeolites annealing at a temperature of $500{ }^{\circ} \mathrm{C}$ restores the specific surface area by removing moisture from the micro- and mesoporous system. In the study of zeolites, such heat treatment is similar to the annealing at the final stage of their preparation does not lead to structure destruction and is recommended.

\subsubsection{Measurement in the given range of the relative partial pressures of the adsorbate gas $P / P_{0}$}

The range selection of $P / P_{\mathrm{o}}$ values is determined by the investigated porous structure parameter. The measurement of the specific surface area by the BET method, the external surface and the construction of the size distribution of mesopores suggest the choice of different study modes.

For example, the $P / P_{\mathrm{o}}$ parameters that are selected on the Sorbi MS device used in this work are listed in Table 4.

\subsection{The micropores volume determination of a series of zeolite compositions by the Sing and t-plot methods}

For the successful and high-quality application of porous materials, the control of their parameters and properties is an important criterion. Analysis of microporous structure parameters in zeolite compositions was carried out in
Table 1 Selected masses for various series of zeolite compositions

\begin{tabular}{|c|c|c|c|c|}
\hline Series & \multicolumn{2}{|c|}{$\mathrm{BEA}+2 \mathrm{MNaOH}$} & \multicolumn{2}{|r|}{ BEA } \\
\hline Mass, mg & 83 & 150 & 49 & 211 \\
\hline $\begin{array}{l}\mathrm{S}_{\mathrm{sp}} \text { value } \\
\text { at standard } \\
\text { conditions of } \\
\text { sample } \\
\text { preparation, } \\
\mathrm{m}^{2} / \mathrm{g}\end{array}$ & 296.6 & $\begin{array}{l}\text { Exceeding } \\
\text { the } \\
\text { maximum } \\
\text { measurable } \\
\text { desorption } \\
\text { signal }\end{array}$ & 303.4 & $\begin{array}{l}\text { Exceeding } \\
\text { the } \\
\text { maximum } \\
\text { measurable } \\
\text { desorption } \\
\text { signal }\end{array}$ \\
\hline
\end{tabular}

Table 2 Specific area values for different sample preparation modes

\begin{tabular}{llll}
\hline & $T$ Prep,${ }^{\circ} \mathrm{C}$ & $t$ Prep, min & $S_{\mathrm{sp}}, \mathrm{m}^{2} / \mathrm{g}$ \\
\hline & - & - & 99.79 \\
BEA+2MNaOH & 150 & 20 & 296.6 \\
& 150 & 45 & 399.2 \\
& 300 & 15 & 434.4 \\
\hline
\end{tabular}

Table 3 Specific area values for different sample preparation modes before and after annealing at $500{ }^{\circ} \mathrm{C}$

\begin{tabular}{llll}
\hline & $T$ Prep, ${ }^{\circ} \mathrm{C}$ & $t$ Prep, $\min$ & $S_{\mathrm{sp}}, \mathrm{m}^{2} / \mathrm{g}$ \\
\hline \multirow{2}{*}{ BEA before annealing } & - & - & 170 \\
& 150 & 60 & 366.1 \\
BEA after annealing & - & - & 453 \\
BEA after annealing, & - & - & 300 \\
3 days later & 150 & 60 & 470 \\
\hline
\end{tabular}

of $P / P_{\mathrm{O}}$

Table 4 The value range of $P / P_{0}$

\begin{tabular}{lll}
\hline $\begin{array}{l}\text { Investigated } \\
\text { parameter }\end{array}$ & Method & $\begin{array}{l}\text { Range of relative } \\
\text { partial pressures } \\
\text { of adsorbate gas } P / P_{\mathrm{O}}\end{array}$ \\
\hline $\begin{array}{l}\text { Specific surface area } \\
\text { Micropore indication }\end{array}$ & t-plot method & $\mathbf{1 5 \%} \%$ to $20 \%$ \\
$\begin{array}{l}\text { External surface } \\
\text { of mesopores, size } \\
\text { distribution } \\
\text { of mesopores }\end{array}$ & $\begin{array}{l}\text { Capillary } \\
\text { condensation } \\
\text { of an inert gas }\end{array}$ & $6 \%$ to $97 \%$ \\
\hline
\end{tabular}

this paper. Zeolites of the type ZSM-5 (samples 1,3 in Table 5) and BETA (samples 2,4-6 in Table 5) were used.

Studies of the zeolites porous structure were carried out by low-temperature nitrogen adsorption on a Sorbi MS device (t-plot method).

As an alternative method for estimating the micropores volume, a comparative sing method is proposed. It is based on the use of the relative adsorption value $\alpha_{\mathrm{s}}$ on the reference sample.

The value $\alpha_{\mathrm{s}}$ is calculated from the ratio of the current adsorption value $V$ to adsorption at the relative pressure $P / P_{\mathrm{O}}=0.4$. The reference is a non-porous zeolite (without heating) of the same chemical nature as the sample under study. Using normalized value we rebuild previously constructed adsorption isotherms into dependence of type $V=f\left(V / V_{0.4}\right)$, replacing relative pressure by value $\alpha_{\mathrm{s}}$. The segment, cut off on the ordinate axis, is the value by which the micropores volume is then calculated.

The obtained t-plot and Sing micropore volume values are shown in Table 5 . 
Table 5 Micropore volume values by the t-plot and Sing method

\begin{tabular}{|c|c|c|c|c|c|}
\hline $\begin{array}{l}\text { Sample } \\
\text { № }\end{array}$ & $\begin{array}{l}\text { Sample composition } \\
\text { zeolite/AH, wt } \%\end{array}$ & AH producer & Peptizer & $\begin{array}{l}\text { Micropores volume } \\
\text { (t-plot method), } \\
\mathrm{cm}^{3} / \mathrm{g}\end{array}$ & $\begin{array}{l}\text { Micropores volume } \\
\text { (Sing method), } \\
\mathrm{cm}^{3} / \mathrm{g}\end{array}$ \\
\hline 1 & ZSM-5 & - & - & 0.07 & 0.07 \\
\hline 2 & BEA & - & - & 0.066 & 0.09 \\
\hline 3 & $70 \mathrm{ZSM}-5 / 30 \mathrm{AH}$ & Sasol & aqueous solution of nitric acid & 0.053 & 0.065 \\
\hline 4 & 70 BEA /3O AH-1 & Sasol & aqueous solution of nitric acid & 0.039 & 0.074 \\
\hline 5 & $70 \mathrm{BEA} / 30 \mathrm{AH}-2$ & OAO AZK and OS & aqueous solution of nitric acid & 0.1 & 0.1 \\
\hline 6 & $70 \mathrm{BEA} / 30 \mathrm{AH}-3$ & OAO AZK and OS & $\begin{array}{l}\text { mixture of aqueous solutions } \\
\text { of nitric acid and ammonia }(1: 1)\end{array}$ & 0.072 & 0.097 \\
\hline
\end{tabular}

As it can be seen, the micropore volume values calculated by Sing do not differ significantly compared to the values taken from the Sorbi MS device. Thus, it is possible to estimate the volume of micropores by both the t-plot method and the comparative Sing method. The analysis showed that the largest micropores volume $(0.1 \mathrm{ml} / \mathrm{g})$ is typical for samples of series 5 , where in the synthesis process an aqueous solution of nitric acid was used as a peptizer, and aluminum hydroxide from the manufacturer OAO AZK and OS was used as a binder. Replacement of the peptizer (sample 6 in Table 5) led to a slight decrease in the micropores volume in the composition. However, such a replacement results in an increase in the total specific surface area [8] and the total pore volume.

\section{Conclusions}

The paper considers the method application features of nitrogen thermal desorption for the study of micromesoporous materials on the example of zeolite composition.

The recommended mass values for obtaining a stable desorption signal and the recommended modes of sample preparation of zeolite compositions were selected. As a rule, in the study of materials by the thermal desorption method of inert gases, an insufficient mass of the sample can act as a significant limitation for the analysis. In the case of studying zeolite compositions, on the contrary, too large an adsorbent mass can lead to an incorrect sensor signal for thermal conductivity and peak truncation.

Nitrogen adsorption at $77 \mathrm{~K}$ on a series of zeolite compositions was investigated. It was shown that using analysis sorption methods, it is possible to estimate the volume micropores by the t-plot and Sing method.

\section{References}

1. Everett D. Manual of Symbols and Terminology for Physicochemical Quantities and Units, Appendix II: Definitions, Terminology and Symbols in Colloid and Surface Chemistry. Pure and Applied Chemistry. 1972;31(4):577-638. doi:10.1351/pac197231040577

2. Wang G, Wang K, Ren T. Improved analytic methods for coal surface area and pore size distribution determination using 77K nitrogen adsorption experiment. Int J Min Sci Technol. 2014;24(3):329-334. doi:10.1016/j.ijmst.2014.03.007

3. Gavrilov VY. Fiziko-himicheskie osnovy adsorbcionnogo analiza dispersnyh i poristyh materialov [Physicochemical bases of adsorption analysis of dispersed and porous materials]. Novosibirsk: NCTC; 2007. 67 p. Russian.

4. Zelenka T. Adsorption and desorption of nitrogen at $77 \mathrm{~K}$ on micro- and mesoporous materials: Study of transport kinetics. Journal of Microporous and Mesoporous Materials. 2016;227:202-209. doi:10.1016/j.micromeso.2016.03.009

5. Nguyen TB, Huang CP, Doong RA, Chen CW, Dong CD. CoO-3D ordered mesoporous carbon nitride (CoO@mpgCN) composite as peroxymonosulfate activator for the degradation of sulfamethoxazole in water. Journal of Hazardous Materials. 2021;401:123320. doi:10.1016/j.jhazmat.2020.123326

6. Dong GY, Tian GY ,Gong LL, Tang QG. Mesoporous zinc silicate composites derived from iron ore tailings for highly efficient dye removal: Structure and morphology evolution. Journal of Microporous and Mesoporous Materials. 2020;305:110352. doi:10.1016/j.micromeso.2020.110352

7. Hadis M, Jafar T, Babak M. Enhanced nitrogen adsorption capacity on $\mathrm{Ca}^{2+}$ ion-exchanged hierarchical X zeolite. Separation and Purification Technology. 2021;264:118442. doi:10.1016/j.seppur.2021.118442

8. Kononova IE, Maraeva EV, Skornikova SA, Moshnikov VA. Influence of binder on porous structure of zeolite compositions and their catalytic activity. Glass Physics and Chemistry. 2020;46(2):162-169. doi:10.1134/S1087659620020066

9. Gracheva IE, Moshnikov VA, Maraeva EV, Karpova SS, Alexsandrova OA, Alekseyev NI, Kuznetsov VV, Olchowikc G, Semenov KN, Startseva AV, Sitnikov AV, Olchowikc JM. Nanostructured materials obtained under conditions of hierarchical self-assembly and modified by derivative forms of fullerenes. Journal of non-crystalline solids. 2012;358(2):433-439. doi:10.1016/j.jnoncrysol.2011.10.020

10. Maraeva EV, Permiakov NV, Kedruk YY, Gritsenko LV, Abdullin KhA. Creating a virtual device for processing the results of sorption measurements in the study of zinc oxide nanorods. Chimica Techno Acta. 2020;7(4):154-158. doi:10.15826/chimtech.2020.7.4.03 